\title{
COMPARATIVE STUDY OF PREVALENCE OF METABOLIC SYNDROME IN DEPRESSED PATIENTS ATTENDING A TERTIARY CARE CENTRE IN EASTERN INDIA
}

\author{
Somsubhra Chattopadhyay1, Kaberi Bhattacharya², Debesh Roy³, Seshadri Sekhar Chatterjee ${ }^{4}$, Sanjay Sadhukhan ${ }^{5}$ \\ ${ }_{1}^{1}$ Assistant Professor, Department of Psychiatry, College of Medicine and Sagar Dutta Hospital, Kolkata, West Bengal. \\ ${ }^{2}$ Assistant Professor, Department of Psychiatry, Midnapore Medical College and Hospital, West Midnapore, West Bengal. \\ ${ }^{3}$ Associate Professor, Department of Biochemistry, Bankura Sammilani Medical College, Bankura, West Bengal. \\ ${ }^{4}$ RMO cum Clinical Tutor, Department of Psychiatry, Medical College and Hospital, Kolkata, West Bengal. \\ 5 Professor of Public Health, All India Institute of Hygiene and Public Health, Kolkata, West Bengal.
}

\section{BACKGROUND}

ABSTRACT

Metabolic syndrome (MS) is rampant all over the world. Depression is expected to be the second most common cause of loss of DALY (Disability Adjusted Life Events) by 2020 after coronary artery disease as per WHO (World Health Organization). Previous studies show connection between depression and MS. Most studies are from western world. We tried to find MS in clinically depressed patients attending a tertiary care hospital of Eastern India.

Aims and Objectives- Our objective was to assess the prevalence of MS in patients with depression who had never been treated with antidepressants for their depressive disorder and compare the same with a matched group of healthy patients. We followed the criteria proposed by the International Diabetes Federation (IDF) in diagnosing MS.

\section{MATERIALS AND METHODS}

There are two groups. Study group (51) comprised clinically depressed patients as per ICD-10. Second group comprised healthy controls (46) who were matched for age, sex, gender, education and socioeconomic profile. Anthropometric measurement and assessment of metabolic parameters were noted in both groups. Cases were given 'Beck Depressive Inventory (BDI)' to assess severity of depression.

\section{RESULTS}

$31.4 \%$ of study group and $17.4 \%$ of control group had MS. Most common of MS among study group was low HDL and among control group was central obesity.

\section{CONCLUSION}

Our study strongly indicates association of depression and MS. Low HDL was the most common abnormality in our patient group, in which females were more in number.

\section{KEY WORDS}

Metabolic Syndrome; Depression; India.

HOW TO CITE THIS ARTICLE: Chattopadhyay S, Bhattacharya K, Roy D, et al. Comparative study of prevalence of metabolic syndrome in depressed patients attending a tertiary care centre in Eastern India. J. Evolution Med. Dent. Sci. 2018;7(17):20892094, DOI: $10.14260 /$ jemds/2018/468

\section{BACKGROUND}

Major depressive disorder is a psychiatric illness that encompasses both emotional and physical symptoms. The condition affects an estimated 340 million people worldwide (Gerden JF, 2003). ${ }^{1}$ Whereas metabolic syndrome is defined by a combination of central obesity, high blood pressure, low high-density lipoprotein (HDL) cholesterol, elevated triglycerides and hyperglycaemia. These clustered risk factors have been associated with the development of type 2 diabetes and cardiovascular disease (Reaven GM, 1988). ${ }^{2}$

'Financial or Other Competing Interest': None.

Submission 30-03-2018, Peer Review 10-04-2018,

Acceptance 13-04-2018, Published 23-04-2018.

Corresponding Author:

Dr. Kaberi Bhattacharya,

Assistant Professor

Department of Psychiatry,

Midnapore Medical College and Hospital

West Midnapore,

West Bengal, India.

E-mail: bkaberi.acharyya@gmail.com

DOI: $10.14260 /$ jemds $/ 2018 / 468$

\section{(c) $($ ) $\ominus$}

The association between depression and the MS has been studied over the past decade (BE Cohen, 2010; TH Heiskanen, 2006; LS Kinder, 2004). ${ }^{3}$ These also include visceral accumulation of body fat (Bjorntorp, 2001; Brown et al 2004),4,5 elevated glucose levels (Weber et al, 2000), 6 hypertension (Davidson et al, 2000)7 and elevated levels of blood lipids (Nakao et al, 2001; Rowan et al, 2005).8,9 It should be noted, though, that high levels of depression have also been associated with extreme and chronic low levels of blood lipids (Morgan et al, 1993; Steegmans et al, 2000; Suarez EC, 1999).10,11,12

More recently it has been suggested that MS may be intermediate in the pathway between depression and CVD (Cerebrovascular Disease) (Cohen BE et al, 2010; Kinder LS et al, 2004).3,13 Multiple pathophysiological mechanisms underlying the association between depression and MS have been proposed. One mechanism is neuroendocrine and involves overstimulation of the hypothalamic-pituitaryadrenal (HPA) axis, which leads to excess cortisol secretion and has been associated with both the development of depression and the MS components (Rosmond R \& Bjorntorp P, 2000; Holsboer F, 2001).14,15 Another indirect pathway is through adverse health behaviours associated with 
depression, such as cigarette smoking, excessive use of alcohol and a sedentary lifestyle which may be used as coping responses and subsequently increase risk of MS and CVD (Vaccino $\mathrm{V}$ et al, 2008). ${ }^{16}$

Most of the studies, which have evaluated the prevalence of MS in patients of depression have emerged from the West. Studies which have studied the relationship of MS with depression can broadly be understood as studies which evaluated the prevalence of MS in depressed patients and as studies which have evaluated the prevalence of MS in patients attending general hospital or the community-based population. Studies which have evaluated the prevalence of MS in depressed patients, of sample size varying between 60 and 230 have reported that prevalence rates vary from $25 \%$ to $41 \%$ (Heiskanen TH et al, 2006; Richter $\mathrm{N}$ et al, 2010).17,18

There is lack of data from eastern countries like India. One study evaluated the prevalence of MS in patients with depression (first episode or recurrent depressive disorder according to ICD 10) and reported prevalence of MS to be $44 \%$ according to NCEP-ATP criteria. But that study included patients with depression who were on treatment (Aggarwal $\mathrm{M}$ et al, 2012). Another study reported a significant elevation of serum total cholesterol in depressed patients compared with normal controls and the significance of these findings persisted even after controlling for various confounders (Dass PP et al, 2010).19

In this background, the present study aimed at assessing the prevalence of MS in patients with depression who had never been treated with antidepressants for their depressive disorder and compare the same with a matched group of healthy controls.

\section{MATERIALS AND METHODS \\ Study Design}

This descriptive comparative study was designed to assess the frequency of metabolic syndrome in depression patients in naturalistic and clinical practice settings.

\section{Study Setting}

Study was done in outdoor of Psychiatry and Biochemistry Department of Medical College, Kolkata.

\section{Sample Size}

We took all willing patients who attended psychiatry outdoor during the stipulated time period. Controls were willing caregivers of psychiatry outdoor and indoor who fulfilled the criteria.

\section{Study Population}

The study group comprised patients of psychiatry outdoor diagnosed to have depressive disorders (first-episode depression, recurrent depressive disorder and dysthymia) as per ICD-10. The control group included healthy persons that are matched to the disease group for the socio-demographic variables of age, gender, education and neighbourhood on a one-to-one basis. We selected controls from the caregivers of the patients of both indoor and outdoor.

The inclusion criteria for the patient with depression were age more than 18 years, drug-naïve (never received any psychotropic agent continuously for more than two weeks or not so in the last three months, ascertained by information obtained from patients and the caregiver and wherever available review of treatment records), and free from any psychiatric or physical comorbidity (other than hypertension and diabetes mellitus), which can influence the metabolic profile. The healthy control group was recruited from the healthy caregivers of the patients, who did not have any past or family history of mental illness.

\section{Definition of MS}

Different criteria defining MS are available. The criteria proposed by the National Cholesterol Education Program Adult Treatment Panel III (ATP III) (Expert Panel on Detection and Treatment of High Blood Cholesterol in Adults) ${ }^{20}$ with revision in 2005 by the American Heart Association/ National Heart, Lung and Blood Institute (updated ATP III) (Grundy SM et al, 2005)21 and the International Diabetes Federation (IDF) (Alberti KG et al, $2005)^{22}$ are widely accepted, as these provide a differential profile for populations of Asian origin. These definitions lay emphasis on abdominal obesity (abdominal circumference of $\geq 90$ and $\geq 80 \mathrm{~cm}$ respectively for men and women of Asian origin, and of $102 \mathrm{~cm}$ and $88 \mathrm{~cm}$ respectively for non-Asians). The other criteria are triglyceride levels $>150 \mathrm{mg} / \mathrm{dL}$, high density lipoproteins (HDL) $<40 \mathrm{mg} / \mathrm{dL}$ and $50 \mathrm{mg} / \mathrm{dL}$ for men and women respectively, a systolic blood pressure $\geq 130$ $\mathrm{mm}$ of mercury ( $\mathrm{Hg}$ ) or a diastolic blood pressure $\geq 85 \mathrm{mmHg}$ and fasting plasma glucose levels $\geq 100 \mathrm{mg} / \mathrm{dL}$. Unlike the WHO criteria (World Health Organization, 1999) ${ }^{23}$ for MS proposed earlier, the IDF and updated ATP definitions also have the advantage of being easily measurable and not requiring specialised investigations. The IDF and updated ATP III criteria overlap and identify similar patients. The major difference between these is the necessity of central obesity for making a diagnosis, while the IDF definition needs central obesity plus any other two or more out of five criteria; the updated ATP III definition requires any three or more of the five criteria. We followed IDF.

After being approved by the Ethics Review Committee of the institute, all patients were recruited on obtaining informed consent. The study was carried out in the outpatient department of Psychiatry and Biochemistry from August to November 2014

\section{Anthropometric and Metabolic Assessments}

Socio-demographic and clinical information was collected on a semi-structured proforma designed for the study. Physical evaluation included measurements of body weight in kilogram (KG), height in centimetres (cm) and waist circumference (in $\mathrm{cm}$ ) and recording of blood pressure (BP). Waist circumference was measured in $\mathrm{cm}$ using a measuring tape in the horizontal plane midway between the inferior margin of the ribs and the superior border of the iliac crest; measurement being recorded at the end of normal expiration in the standing position. The triglyceride (TG), high-density lipoprotein (HDL), fasting blood sugar (FBS) and the lowdensity lipoprotein (LDL) levels (mg/dL) were measured at the routine biochemistry laboratory of the hospital using fasting venous blood samples. Measurements included weight in kilogram (kg) using a common bathroom scale and height in $\mathrm{cm}$ by a calibrated scale routinely used for this purpose by the nursing staff. The body mass index (BMI) was calculated from the weight and height $(\mathrm{kg} / \mathrm{m} 2)$. By using standard mercury manometer, at least two readings at five-minute 
intervals were taken to measure the BP in supine position. If $\mathrm{BP}$ was to be high ( $>140 / 90)$, then a third reading after 30 minutes was obtained; the lowest of these reading was taken.

Patients and healthy subjects in the control group found to have metabolic abnormalities were informed about the same. They were explained about the need for proper diet and regular exercise and referred for specialist care whenever required.

\section{Psychological Assessment}

Severity of depression was assessed among patients using Bengali version of Beck Depression Inventory (BDI) (Beck A et al, 1988). ${ }^{24}$

\section{Statistical Analysis}

SPSS version 16 was used for analysis. Frequencies with percentages were calculated for categorical variables and mean and standard deviation were calculated for continuous variables. Those with and without MS were compared using chi-square test and t-tests.

\section{RESULTS}

\section{Demographic and Clinical Characteristics (Table 1)}

- The study sample comprised of 51 patients with depressive disorders and 46 number of subjects in healthy control group. As detailed in Table 1, mean age of the patients with depression was 32 years and that of the control group was 35 years. The mean duration of education of the participants in the depression group was $7.10 \mathrm{yrs}$. and that of subjects in the healthy control group was 8.17 yrs. Mean income per capita per month in patient and control group was Rs. 1277 and Rs. 947 respectively. All these differences were not significant statistically.

- In both groups majority of subjects were females, $68.6 \%$ in patients and $59.6 \%$ in control group, but this difference was insignificant.
- In both groups majority of subjects were married, belonged to Hindu religion and came from rural backgrounds. Most patients and controls were females and homemakers.

- The mean duration of illness was 18.4 months (SD: 27.11; range: 1 - 144 months).

- $38(74.5 \%)$ patients had major depressive disorder, $10(19.6 \%)$ had dysthymia, while 3 (5.9\%) were suffering from recurrent depressive disorder.

\section{Metabolic Parameters (Table 2)}

Among the patients, 16 (31.4\%) had metabolic syndrome whereas in controls it was $8(17.4 \%)$.

Among all the components of metabolic syndrome most common among patients was low HDL 34 (66.7\%) and in the control group it was central obesity 22 (47.8\%). The least common component in both the groups was raised FBS $31.4 \%(n=16)$ and $17.4 \%(n=8)$ respectively.

With respect to subtypes of depressive disorder, the prevalence of MS in subjects with $1^{\text {st }}$ episode major depressive disorder is $35.71 \%$ (10 out of 28 ), $50 \%$ in those with dysthymia (5 out of 10 ) and $33.33 \%$ in among patients of recurrent depressive disorder.

Among 51 patients 23 (45.09\%) were obese (BMI > 25), whereas in control group it was $60.87 \%$ (28 out of 46 ).

\section{Among the Patient Group (Table 3)}

Those who have MS did not have higher BDI score than the other group who had not. MS group had longer duration of disorder, but this difference was not significant. Among all the components of MS, this group had significant higher level of TG and abdominal circumference. This group also had significantly higher weight as well as BMI.

\section{Among all the Participants (Table 4)}

Among all those with MS were significantly older, had higher abdominal obesity, serum TG level, weight and BMI.

\begin{tabular}{|c|c|c|c|}
\hline Variable & Patient Group N=51 & Control Group N=46 & Chai Square/ T value \\
\hline Age (SD) & $32.94(10.53)$ & $35.17(12.60)$ & .950 \\
\hline Education (SD) & $7.10(4.76)$ & $8.17(3.07)$ & .440 \\
\hline Income (SD) & $1277.45(1438.10)$ & $947.83(1516.39)$ & 1.09 \\
\hline Sex (\%) & $16(31.4)$ & $18(38.3)$ & .633 \\
Male & $35(68.6)$ & $28(59.6)$ & .945 \\
Female & $42(82.4)$ & $38(82.6)$ & \\
\hline Marital Status (\%) & $8(15.7)$ & $8(17.4)$ & \\
Married & $1(2)$ & $22(47.8)$ & 2.187 \\
Unmarried & $33(64.7)$ & $24(52.2)$ & \\
Widowed & $18(35.3)$ & $24(52.2)$ & \\
\hline Religion (\%) & $18(35.3)$ & $22(47.8)$ & \\
Hindu & $33(64.7)$ & & \\
Non-Hindu & Table 1. Socio-Demographic Profile of Patient and Control Group & \\
\hline Neighbourhood (\%) &
\end{tabular}

$* \mathrm{p}<.05$. 


\begin{tabular}{|c|c|c|c|}
\hline Variable & Patient Group N=51 & Healthy Control Group N=46 & Chi-Square/ T value \\
\hline Body weight (kg) (SD) & 55.92 & 60.91 & 2.074 \\
\hline BMI (SD) & 22 & 23 & 1.006 \\
\hline $\begin{array}{c}\text { BMI Status (\%) } \\
\text { Underweight }(>18.5) \\
\text { Normal }(18.5-24.9) \\
\text { Pre-obese }(25-29.9) \\
\text { Obese Grade } 1(30-34.9) \\
\text { Obese Grade } 2(35-39.9) \\
\text { Obese Grade } 3>40\end{array}$ & $\begin{array}{c}2.380 \\
7(13.7) \\
21(41.2) \\
10(19.6) \\
11(21.6) \\
2(3.9)\end{array}$ & $\begin{array}{c}2.269 \\
8(17.4) \\
10(21.7) \\
12(26.1) \\
6(13) \\
10(21.7)\end{array}$ & 1.006 \\
\hline WC (cm) (SD) & $79(10.2)$ & $81(7.8)$ & .995 \\
\hline TG levels (mg/dL) (SD) & $137(10.2)$ & $134(11.6)$ & -.302 \\
\hline HDL levels (mg/dL) (SD) & $44(5.2)$ & $45(7.2)$ & .747 \\
\hline FBS levels (mg/dL) (SD) & $96.84(9.7)$ & $89.78(7.9)$ & -1.598. \\
\hline Central obesity (\%) & 20 & 22 & .730 \\
\hline $\mathrm{BP}(\geq 130 \mathrm{mmHg} / \geq 85 \mathrm{mmHg})(\%)$ & 26 & 14 & 4.213 \\
\hline $\mathrm{TG} \geq 150 \mathrm{mg} / \mathrm{dL}(\%)$ & 17 & 18 & .352 \\
\hline Low HDL ( $<40 \mathrm{mg} / \mathrm{dL}$ M, $<50 \mathrm{mg} / \mathrm{dL}$ F) (\%) & 34 & 18 & .456 \\
\hline FBS $\geq 100$ mg/dL (\%) & 16 & 8 & 2.539 \\
\hline MS (\%) & 16 & 8 & 2.539 \\
\hline $\begin{array}{c}\text { MS Criteria Fulfilled (\%) } \\
0 \\
1 \\
2 \\
3 \\
4 \\
5\end{array}$ & $\begin{array}{c}5(9.8 \%) \\
11(21.6 \%) \\
13(25.5 \%) \\
14(27.5 \%) \\
4(7.8 \%) \\
4(7.8 \%)\end{array}$ & $\begin{array}{c}10(21.7 \%) \\
6(13.0 \%) \\
16(34.8 \%) \\
14(30.4 \%) \\
- \\
-\end{array}$ & $11.220^{*}$ \\
\hline
\end{tabular}

${ }^{*} \mathrm{p}<.05$

\begin{tabular}{|c|c|c|c|}
\hline Variable & $\begin{array}{c}\text { Patients with MS } \\
\mathbf{N = 1 6}\end{array}$ & $\begin{array}{c}\text { Patients without } \\
\text { MS N=35 }\end{array}$ & Sig. \\
\hline BDI score (SD) & $21.75(7.8)$ & $24.43(8.9)$ & .312 \\
\hline Age (SD) & $39.31(5.6)$ & $30.03(7.9)$ & $.003^{*}$ \\
\hline Education (SD) & $6.75(4.7)$ & $8.29(2.7)$ & .290 \\
\hline Income (SD) & $1375.00(1215.00)$ & $1232.86(1120.00)$ & .747 \\
\hline Abdominal Circumference (SD) & $90.344(12.7)$ & 74.757 & $.000^{*}$ \\
\hline Duration & $25.06(12.5)$ & $15.37(9.8)$ & .240 \\
\hline TG & $170.38(23.7)$ & $123.06(23.88)$ & $.013^{*}$ \\
\hline FBS & $107.88(24.6)$ & $91.80(18.55)$ & .058 \\
\hline HDL & $44.12(7.8)$ & $45.09(4.8)$ & .296 \\
\hline Weight & $63.69(12.9)$ & $52.37(11.8)$ & $.000^{*}$ \\
\hline BMI & $26.010(10.09)$ & $21.342(13.8)$ & $.000^{*}$ \\
\hline
\end{tabular}

$* \mathrm{p}<.05$

\begin{tabular}{|c|c|c|c|}
\hline Variable & $\begin{array}{c}\text { Participants with MS } \\
\mathbf{N = 2 4}\end{array}$ & Participants without MS N=73 & Sig. \\
\hline Age (SD) & $39.88(8.9)$ & $32.07(5.7)$ & $.004^{*}$ \\
\hline Education (SD) & $6.92(2.3)$ & $8.33(3.3)$ & .138 \\
\hline Income (SD) & 1070.83 & $1137.67(1342.60)$ & .849 \\
\hline Abdominal Circumference (SD) & $91.146(23.33)$ & $77.295(20.66)$ & $.000^{*}$ \\
\hline TG (SD) & $169.50(42.56)$ & $125.49(34.32)$ & $.000^{*}$ \\
\hline FBS (SD) & $100.50(13.80)$ & $91.19(9.8)$ & .071 \\
\hline HDL (SD) & $44.58(12.07)$ & 45.10 & .398 \\
\hline Weight (SD) & $63.69(13.09)$ & $52.37(10.87)$ & $.000^{*}$ \\
\hline BMI (SD) & $25.80(10.45)$ & $22.38(9.87)$ & $.001^{*}$ \\
\hline \multicolumn{2}{|c|}{ Table 4. Socio-Demographic Variables, Clinical Variables and Metabolic Parameters } \\
of Participants with and without MS & \\
\hline
\end{tabular}

${ }^{*} \mathrm{p}<.05$ 


\section{DISCUSSION}

Prevalence of metabolic syndrome in patients with depressive disorder as well as association between metabolic syndrome (and components of metabolic syndrome) and depression was investigated in different studies. Relation between MS and depression is variable. Not all investigations showed association between metabolic syndrome and depression. In the investigation that aimed to estimate the association between metabolic syndrome (According to IDF, NCEP/ ATP-III and ATP-IIIa criteria) and depressive symptoms among the employees of a medical school in Colombia, no association was observed between metabolic syndrome and depression (Diaz Martinez L et al, 2007). ${ }^{25}$ Furthermore, the study that aimed to characterise the relationship between major depression and the metabolic syndrome in a large community based sample of Australian men and women aged 26 - 90 years (According to NCEP APIII guidelines) showed that there was no association between a lifetime history of major depression and the presence of the metabolic syndrome. There was a weak association between depression and low high-density lipoprotein cholesterol, but not with other component criteria of the metabolic syndrome (Foley DL et al, 2010).26 Among Indian studies one crosssectional study found $37 \%$ of the depressed patients had MS, wherein their age, sex matched healthy counterparts' prevalence of MS was $16.3 \%$ and this difference was significant (Grover S et al, 2013).27 Among our patients $16(31.4 \%)$ had metabolic syndrome, whereas in controls it was $8(17.4 \%)$. Though percentage was more in the patient group, it was not significant statistically.

In one study that aimed to examine gender effects and the role of cortisol in the association between depressive symptoms and metabolic risk, depressive symptoms were not associated with the metabolic syndrome as entity in the total sample of men and women separately. In men, an association between depressive symptoms and variables of the metabolic syndrome was not found. In women, depressive symptoms were associated with several variables of the metabolic syndrome. Elevated afternoon and evening cortisol appear to partially mediate this association (Muhtz C et al, 2009). ${ }^{28}$ Kinder LS et al in 2004 also found that women but not men, with a history of major depressive episodes were twice as likely to have the MS compared with those with no history of depression. In addition, among these women depression was significantly associated with high blood pressure and high triglyceride level and a trend was observed toward an association with low HDL and large waist circumference. So it is almost proved that men and women are affected differentially.

In our patients among all the components of metabolic syndrome, most common was low HDL 34 (66.7\%) and in the control group it was central obesity 22 (47.8\%). The least common component in both the groups was raised FBS $31.4 \%(\mathrm{~N}=16)$ and $17.4 \%(\mathrm{~N}=8)$ respectively. Kinder $\mathrm{LS}$ et al found in 2004 depression appeared to be most closely associated with high blood pressure and high triglyceride level in a population-based health survey of noninstitutionalized US citizens conducted by the National Center for Health Statistics of the Center for Disease Control and Prevention. In another German study ,25\% of the depressed inmates met criteria for MS. $33.3 \%$ met one, $25 \%$ met two, $13.3 \%$ met three and $11.7 \%$ met four components of MS, whereas $16.7 \%$ met none (Richter $\mathrm{N}$ et al, 2010) ${ }^{18}$. In our study percentages were 21.6, 25.5, 27.5, 7.8 and 9.8 respectively. They found hypertension and abdominal obesity as the most commonly occurring MS component in the patients. Grover et al found increased abdominal circumference common as the most common abnormality in both the study group. It was followed by abnormal BP and raised TG in the patient group, while the healthy controls had raised TG level and low HDL level. Like our findings raised FBS level was the least common finding in both the groups. So it is difficult to predict whether any abnormality in any single component of MS can predict future development of MS.

When comparing patients with or without metabolic syndrome, no sex-based prevalence differences were found. Patients with metabolic syndrome were older (mean 39.31 vs. 30.03 years, $\mathrm{p}=.003$ ) showed low depression and low education level, though these differences were not significant (Table 3). The metabolic parameters were not significantly correlated with BDI scores of the patients or the duration of the disorder. In a large population-based study Dunbar JA et al in 2008 found participants with MS were more likely to be older and more depressed. ${ }^{29}$ In our study among the patients who have MS did not have higher BDI score than the other group who had not. MS group had longer duration of disorder, but these differences were not significant. Among all the components of MS, this group had significant higher level of TG and abdominal circumference. This group also had significantly higher weight as well as BMI. Heiskanen et al in 2006 duration of depression does not predict future metabolic syndrome. ${ }^{17}$ There is no evidence at all for a dosage effect of depression on risk for the metabolic syndrome, except in clinical samples with diagnosed cardiovascular disease in other studies also (Vaccarino $\mathrm{V}$ et al, 2008). ${ }^{16}$ So duration and severity of depression are not associated with increased chance of developing MS.

\section{CONCLUSION}

Our study has few limitations like a small sample size and cross-sectional nature. However, in Indian population, very few studies have tried to find out a relation between depression and MS. Though not statistically significant, our study strongly indicates association of depression and MS. Low HDL was most common abnormality in our patient group, in which females were more in number. As this finding is not supported by other Indian studies, which may be due to different variable components of MS in males and females. We also noticed that duration or severity does not affect severity of MS. Larger and prospective studies are required to reach a confirmed conclusion.

\section{REFERENCES}

[1] Greden JF. Physical symptoms of depression: unmet needs. J Clin Psychiatry 2003;64 (Suppl 7):5-11.

[2] Reaven GM. Banting lecture 1988. Role of insulin resistance in human disease. Diabetes 1988;37(12):1595-607.

[3] Cohen BE, Panguluri P, Na B, et al. Psychological risk factors and the metabolic syndrome in patients with coronary heart disease: findings from the Heart and Soul Study. Psychiatry Research 2010;175(1-2):133-7. 
[4] Bjorntorp P. Do stress reactions cause abdominal obesity and comorbidities? Obes Rev 2001;2(2):73-86.

[5] Brown ES, Varghese FP, McEwen BS. Association of depression with medical illness: does cortisol play a role? Biol Psychiatry 2004;55(1):1-9.

[6] Weber B, Schweiger U, Deuschle M, et al. Major depression and impaired glucose tolerance. Exp Clin Endocrinol Diabetes 2000;108(3):187-90.

[7] Davidson K, Jonas BS, Dixon KE, et al. Do depression symptoms predict early hypertension incidence in young adults in the CARDIA Study? Coronary artery risk development in young adults. Arch Intern Med 2000;160(10):1495-500.

[8] Nakao M, Ando K, Nomura S, et al. Depressive mood accompanies hypercholesterolemia in young Japanese adults. Jpn Heart J 2001;42(6):739-48.

[9] Rowan PJ, Haas D, Campbell JA, et al. Depressive symptoms have an independent, gradient risk for coronary heart disease incidence in a random, population-based sample. Annals of Epidemiology 2005;15(4):316-20.

[10] Morgan RE, Palinkas LA, Barrett-Connor EL, et al. Plasma cholesterol and depressive symptoms in older men. Lancet 1993;341(8837):75-9.

[11] Steegmans PH, Hoes AW, Bak AA, et al. Higher prevalence of depressive symptoms in middle-aged men with low serum cholesterol levels. Psychosom Med 2000;62(2):205-11.

[12] Suarez EC. Relations of trait depression and anxiety to low lipid and lipoprotein concentrations in healthy young adult women. Psychosom Med 1999;61(3):2739.

[13] Kinder LS, Carnethon MR, Palaniappan LP, et al. Depression and the metabolic syndrome in young adults: findings from the Third National Health and Nutrition Examination Survey. Psychosomatic Medicine 2004;66(3):316-22.

[14] Rosmond R, Bjorntorp P. The hypothalamic-pituitaryadrenal axis activity as a predictor of cardiovascular disease, type 2 diabetes and stroke. Journal of Internal Medicine 2000;247(2):188-97.

[15] Holsboer F. Stress, hypercortisolism and corticosteroid receptors in depression: implicatons for therapy. Journal of Affective Disorders 2001;62(12):77-91.

[16] Vaccarino V, McClure C, Johnson BD, et al. Depression, the metabolic syndrome and cardiovascular risk. Psychosomatic Medicine 2008;70(1):40-8.

[17] Heiskanen TH, Niskanen LK, Hintikka JJ, et al. Metabolic syndrome and depression: a cross-sectional analysis. J Clinical Psychioatry 2006;67 (9):1422-7.
[18] Richter N, Juckel G, Assion HJ. Metabolic syndrome: a follow-up study of acute depressive inpatients. Eur Arch Psychiatry Clin Neurosci 2010;260(1):41-9.

[19] Das PP, Malhotra S, Chakrabarti S, et al. Elevated total cholesterol in severely depressed patients: role in cardiovascular risk? World J Bio Psychiatry 2010;11(2 Pt 2):321-8.

[20] Expert Panel on Detection, Evaluation and Treatment of High Blood Cholesterol in Adults. Executive summary of the Third report of the National Cholesterol Education Program (NCEP) High Blood Cholesterol in Adults (Adult Treatment Panel III). JAMA 2001;285(19):2486-97.

[21] Grundy SM, Cleeman JI, Daniels SR, et al. Diagnosis and management of the metabolic syndrome: an American Heart Association/National Heart, Lung, and Blood Institute Scientific Statement (executive summary). Circulation 2005;112(17):2735-52.

[22] Alberti KG, Zimmet P, Shaw J. Metabolic syndrome - a new worldwide definition. A Consensus Statement from the International Diabetes Federation. Diabet Med 2006;23(5):469-80.

[23] World Health Organization. Definition, diagnosis and classification of diabetes mellitus and its complications. Report of a WHO consultation. Geneva: WHO, 1999.

[24] Beck AT, Steer RA, Carbin MG. Psychometric properties of the Beck Depression Inventory: twentyfive years of evaluation. Clinical Psychology Review 1988;8(1):77-100.

[25] Díaz-Martínez L, Serrano N, Pinzón J, et al. Lack of association between metabolic syndrome and depressive symptoms in Colombian adults. Revista Med Chil 2007;135(8):990-6.

[26] Foley DL, Morley KI, Madden PAF, et al. Major depression and the metabolic syndrome. Twin Research and Human Genetics 2010;13(4):347-58.

[27] Grover S, Nebhinani N, Chakrabarti S, et al. Metabolic syndrome in Drug-naïve patients with depressive disorders. Indian Journal of Psychological Medicine 2013;35(2):167-73.

[28] Muhtz C, Zyriax BC, Klähn T, et al. Depressive symptoms and metabolic risk: effects of cortisol and gender. Psychoneuroendocrinology 2009;34(7):100411.

[29] Dunbar JA, Reddy P, Davis-Lameloise N, et al. Depression: an important comorbidity with metabolic syndrome in a general population with metabolic syndrome in general population. Diabetes Care 2008;31(12):2368-73. 